\title{
\{Cloud, IoT\}-powered smart weather station for microclimate monitoring
}

Mohamed Fazil Mohamed Firdhous, B.H. Sudantha

Department of Information Technology, University of Moratuwa, Sri Lanka

\begin{tabular}{|c|c|}
\hline Article Info & ABSTRACT \\
\hline Article history: & \multirow{11}{*}{$\begin{array}{l}\text { Monitoring the microclimate is important in many practical situations } \\
\text { involving agriculture, archaeology, and other environments. Microclimate is } \\
\text { defined as the environmental conditions in a small restricted area, that differs } \\
\text { from that of surrounding areas. In certain situations, these conditions are } \\
\text { artificially generated for creating a conducive environment for achieving } \\
\text { better results. Environments such as greenhouses and climate controlled } \\
\text { beehives require to maintain their environments within close variations for } \\
\text { optimum results. Similarly, archaeological sites including show caves, } \\
\text { frescos and parks get disturbed easily by the changes in their immediate } \\
\text { environments. Hence monitoring and managing these environments is a must } \\
\text { for the proper maintenance of them. In this paper, the authors present an IoT } \\
\text { enabled microclimate monitoring weather station that can be installed } \\
\text { anywhere and monitor the required parameters from remotely. The modular } \\
\text { design enables the station to be easily modified to suit any environment. } \\
\text { The weather station collects and transmit data at fixed intervals to the cloud } \\
\text { powered processing system over the mobile communication network. } \\
\text { The sensors have been calibrated using standard calibration techniques with } \\
\text { the aid of conventional devices as reference. The results obtained from the } \\
\text { prototype shows that the weather station works satisfactorily reading the real } \\
\text { environment conditions. }\end{array}$} \\
\hline Received Apr 23, 2019 & \\
\hline Revised Jun 24, 2019 & \\
\hline Accepted Jul 8, 2019 & \\
\hline Keywords: & \\
\hline Cloud computing & \\
\hline Greenhouse & \\
\hline Internet of things & \\
\hline Microclimate monitoring & \\
\hline Sensor networks & \\
\hline & \\
\hline
\end{tabular}

Copyright $(2020$ Institute of Advanced Engineering and Science. All rights reserved.

\section{Corresponding Author:}

Mohamed Fazil Mohamed Firdhous, Department of Information Technology, University of Moratuwa, Moratuwa 10400, Sri Lanka. Email: firdhous@uom.lk

\section{INTRODUCTION}

Microclimate is a set of atmospheric conditions prevailing in a restricted area, that often differs from the surrounding areas [1]. It has been observed that the atmospheric conditions in certain areas such as restricted urban spaces, indoor environments, greenhouses and tourist attractions such as parks, show caves and historical sites slightly differ in terms of temperature, humidity, moisture, light conditions and concentration of different gases and particles [1-6]. Microclimate plays an important role in many aspects of human life. More than half of the world population currently lives in urban areas [1]. This proportion rapidly increases as many parts of the world experience rapid urbanization due to the advances in technology and movement of people towards cities searching for better life. Compared to rural areas, urban regions have a different landscape in terms of reduced vegetation, high concentration of man made structures including buildings, bridges and other permanent, semi permanent and temporary constructions, road networks and other infrastructure, higher population density and heavy concentration and movement of vehicles. Due to the above reasons, urban environments show differing climatic conditions from that of rural areas. Furthermore, urban areas are internally different from one place to another too. There is a heterogeneity in urban landscape in terms of both natural as well as man made environments. Due to the economic background of the residents and the historical developments of specific areas within urban limits, there are drastic differences between the 
size and type of constructions in those areas. Similarly, the types of activities such as commercial, industrial and residential carried out predominantly in specific areas also make the built environments different from one place to another. On the other hand, the vegetative cover also differs from place to place depending on whether the area is identified as commercial, industrial, residential or recreational. Recreational and residential areas tend to have more vegetative cover compared to commercial and industrial areas. Areas witnessing more economic activities have been identified to have more vehicles traversing them compared to other areas. These differences within urban landscapes create microclimates generated by unique combinations of surface materials, their thermal properties, vegetative cover, landscape design and remnants of the natural environment. Hence, understanding the spatial patterns of urban microclimates requires the assessment of the local relationships between different environment quality factors and urban landscape features, at fine spatial scales. Practical implications of improved knowledge surrounding spatial details of urban environment quality factors include impacts for human health and safety, forecasting variations in energy use and municipal administration.

Similar to outdoor environments, indoor environments also show differences in the concentration of various constituents of air [2,7]. Indoor air quality is a major concern for businesses, schools, residents, workers and governments as it impacts the health, comfort, well being and productivity of the occupants of the building [8]. Depending on the type of construction and use of buildings, the constituents of indoor air varies. Main contributors to indoor air pollution include materials used in construction, furniture and consumer products, emissions from office and industrial machinery and fuel combustion during heating and cooking [9]. A greenhouse is an artificial environment created for growing plants under controlled conditions [10]. Measurement and control of climatic conditions are very important for vegetable production in greenhouses [3]. The environmental attributes inside a greenhouse must be closely controlled to suit each plant's requirements for unhindered growth and development. Hence monitoring of the environment parameters inside a greenhouse becomes a prerequisite for the control of the same. Similar to greenhouses, beehives must also be monitored and controlled for better results [11].

Tourists sites including parks, show caves and historical sites also need close monitoring of their climatic conditions for the proper maintenance of them [5, 12-15]. Some tourist attractions receive millions of visitors every year due to their popularity and uniqueness among similar ones across the world. The environments around many of the attractions are characterized by low energy stable environments that are conducive to the growth and well being of flora and fauna and the preservation of historical artifacts located within them [5, 12-14]. These environments maintain a delicate balance between various parameters of the environment that can be easily disturbed by the influx of humans. Hence monitoring the environmental parameters within and around tourist attractions is necessary for maintaining a balance between the preservation the sites along with their resources and the use of them.

The above discussion on the microclimates prevailing in and around special regions clearly show the importance of monitoring the parameters of these environments. In this paper, the authors describes how Internet of Things (IoT) enabled weather stations can be successfully employed for monitoring microclimates. This paper is organized into five different sections as follows: Section 1 gives an overall introduction to the paper along with a brief analysis of microclimates prevailing in and around some selected regions and the need for monitoring them. Section 2 describes the theory and background of Internet of Things in detail with special emphasis on different application areas. Section 3 discusses the methodology adopted in design and development of the proposed smart microclimate monitoring system in detail. Section 4 presents the experiments carried out for testing the system along with the results with an in-depth discussion on the results obtained. Finally, Section 5 concludes the paper with a discussion on how to extend this work to cover other application areas involving microclimate monitoring.

\section{BACKGROUND}

Internet of Things (IoT) is a concept and implementation that has emerged as a new paradigm shaping the Future Internet making it more intelligent, independent and ubiquitous [16]. IoT is made up a collection of objects including both physical and virtual ones that are connected together and communicate with each other over the Internet [17]. The advances made in many related areas including hardware technologies, sensor development, software engineering and networking implementations have contributed to the development of IoT. On the hand, research on Mobile Computing (MC), Pervasive Computing (PC), Wireless Sensor Networks (WSN), and Cyber Physical Systems (CPS) have also being carried out in parallel to IoT with the objective of making this planet a smart one $[18,19]$. Though, the above fields appear to work with different objectives and applications, they have several things in common and rely upon many common underlying technologies including real-time computing, machine learning, security, privacy, signal processing and big data analytics [18, 20]. 
The vision of IoT has extended the reach of the Internet beyond its traditional boundaries of computers as end nodes to real world objects [21]. With IoT, the real world physical objects have become connected with virtual world objects such as computer applications and processes. This not only enables the sensing of the real world events but also control these devices remotely through the Internet making computing truly ubiquitous. The incorporation of computing power into everyday objects makes them smart [22]. These smart objects play a main role in the IoT vision, as the embedded communication capability along with the information processing power would have the potential to revolutionize the utility of these objects. These objects can understand the environment along with their contexts using the sensors embedded in them. These devices can communicate with other similar objects, access the Internet services and interact with people [23]. Digitally upgrading the day to day objects in this manner enhances their functionality beyond their traditional boundaries. This development is already evident today as more and more devices including sewing machines, exercise bikes, electric toothbrushes, washing machines, electricity meters and photocopiers are being computerized and equipped with network interfaces.

On the other hand, through the Internet connectivity of everyday objects, it is possible to determine their states away from long distances. The possibility of up-to-date information collection on natural, physical, and virtual objects and processes enables many aspects of the real world to be observed at a previously unattained level of detail and at negligible cost. This would not only allow for a better understanding of the underlying processes, but also for more efficient control and management of them. The ability to react to events in the physical world in a rapid, automatic, and informed manner not only opens up new opportunities for dealing with complex or critical situations, but also enables a wide variety of business processes to be optimized. The real time interpretation of data from the physical world will most likely lead to the introduction of various novel business services and may deliver substantial economic and social benefits as well. All the above are summarized into a single definition by the European research cluster of IoT (IERC) as "the Internet of Things allows people and things to be connected anytime, anyplace, with anything and anyone, ideally using any path/network, and any service" [24]. Figure 1 shows the elements of IoT in a graphical format.

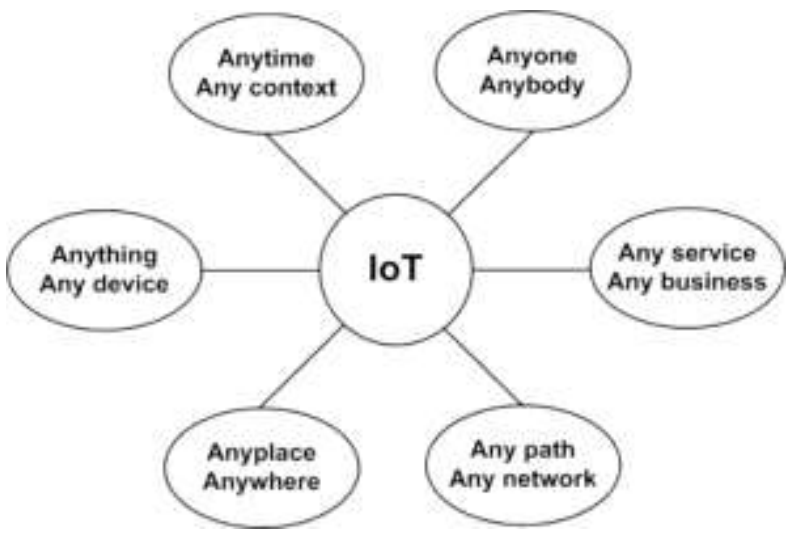

Figure 1. Elements of internet of things [24]

As a result of all the above, IoT based applications have been proposed and implemented in several areas including environment management, environment monitoring, home monitoring, security systems, energy management in public and private spaces, elderly care systems and microclimate monitoring systems [25-28]. The microclimate monitoring system proposed in this research uses both semiconductor sensors and electromechanical transducers along with other supporting elements connected to an IoT board directly. The IoT device has been programmed to collect samples at regular intervals and transfer them to the central processing station. The IoT devices are connected to the Internet and transfers the data to the processing station using the $4 \mathrm{G}$ mobile communication network.

\section{RESEARCH METHODOLOGY}

In order to carry out the proposed work in a scientific manner, an agile research and development methodology was devised and used. The research process started with an extensive literature review on all the relevant areas with special emphasis on understanding all the required background theory and 
applications. Then a suitable hardware platform was selected and was later modified to suit the requirements of microclimate environment monitoring. Once the hardware was developed to meet the requirements, the firmware for data collection, storage and transmission was developed and embedded in the programme storage unit. The central data analyzing station was installed in a high end server and connected to the Internet. Finally the entire system was subjected to extensive testing for proper functioning of the complete system. Deviations from the expected operation were noted and the hardware and software were modified to correct the errors. Subsections 3.1 and 3.2 describe the hardware design and implementation along with the cloud powered data processing and analysis units in detail.

\subsection{Hardware Design of IoT-enabled Weather Station}

Figure 2 shows the architecture of the weather station in a block diagrammatic format. The important components of the design include the microcontroller, local storage unit, communication module, local (LCD) display, sensor panels and the power controller. The sensor panel is a flexible arrangement that can include any type of sensor irrespective of its nature of sensing method or construction. The prototype weather station developed in this work, initially included only two sensors. They are namely a temperature sensor and a humidity sensor, which are two commonly monitored parameters in many microclimate monitoring systems.

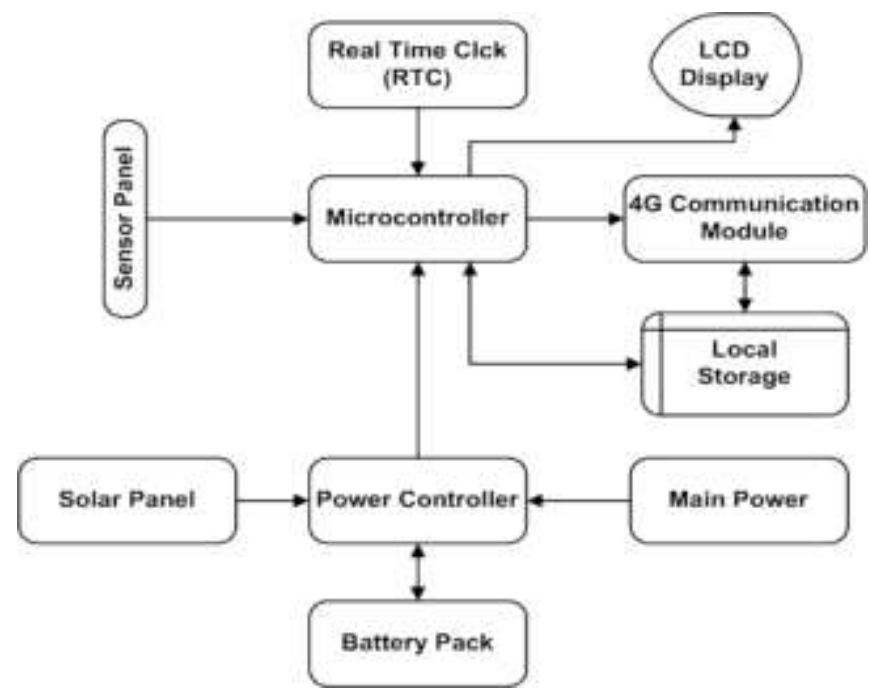

Figure 2. Architecture of the weather station

The other important aspect of this design is the inclusion of a power controller that can integrate multiple power sources. The power controller not only has the capability to integrate multiple power sources, but also regulates the power for supplying constant voltage required by the IoT board. In the prototype, power from two different sources, namely solar power and ac power from the grid have been used. These power sources are used to charge the rechargeable $12 \mathrm{v} \mathrm{Li}$-ion battery pack included in the system. This arrangement will maintain the battery at optimum charge levels throughout the experimentation period. Also the power controller would down convert voltage to the required $5 \mathrm{~V}$ and maintain regulated supply to the IoT board.

The local storage is developed using semiconductor memory combining both volatile SRAM and non-volatile Flash memory units. The Flash memory holds the program code while the SRAM holds the data temporarily until transmitted using the communication module. The $4 \mathrm{G}$ communication module will make a data connection to the mobile communication network and transfer the data the weather data processing station over the Internet. The LCD display unit provides a small local built-in display. The use of this local display is dual purpose as it can be used to verify operation of the unit by the field officers as well as to manually collect data at remote locations. Figures 3(a) and 3(b) show the prototype weather station at the laboratory prototyping stage as well as the final assembly installed outside the laboratory. 


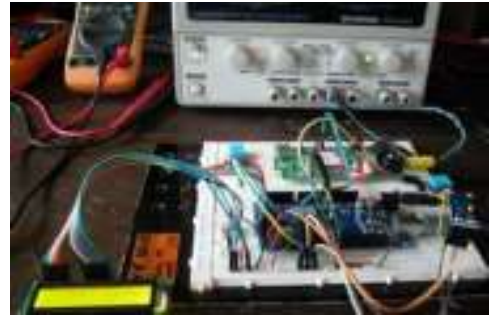

(a)

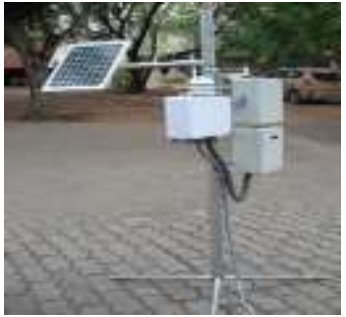

(b)

Figure 3. Prototype weather station

\subsection{Cloud-powered Data Processing and Dissemination Model}

The proposed microclimate monitoring system is made up of three main units including sensing nodes, gateway nodes and the data processing and dissemination station. The sensing nodes monitor the environment on a given set of parameters such as temperature, humidity, light intensity etc. The data collected by the sensing node are transferred to the gateway node, that transmits the data to the processing station. A low power WiFi network is established between the sensing nodes and the gateway node while the data transfer between the gateway node and the processing station through the cellular communication network using the hypertext transfer protocol (http). Figure 4 shows the architecture of the proposed monitoring system. This system can be easily extended to cover large areas by increasing the number of sensing nodes as well as gateway nodes while hosting the processing station on the cloud. Cloud systems provide better resilience, security, and availability at lower cost compared to the conventional in-house hosted systems [29, 30].

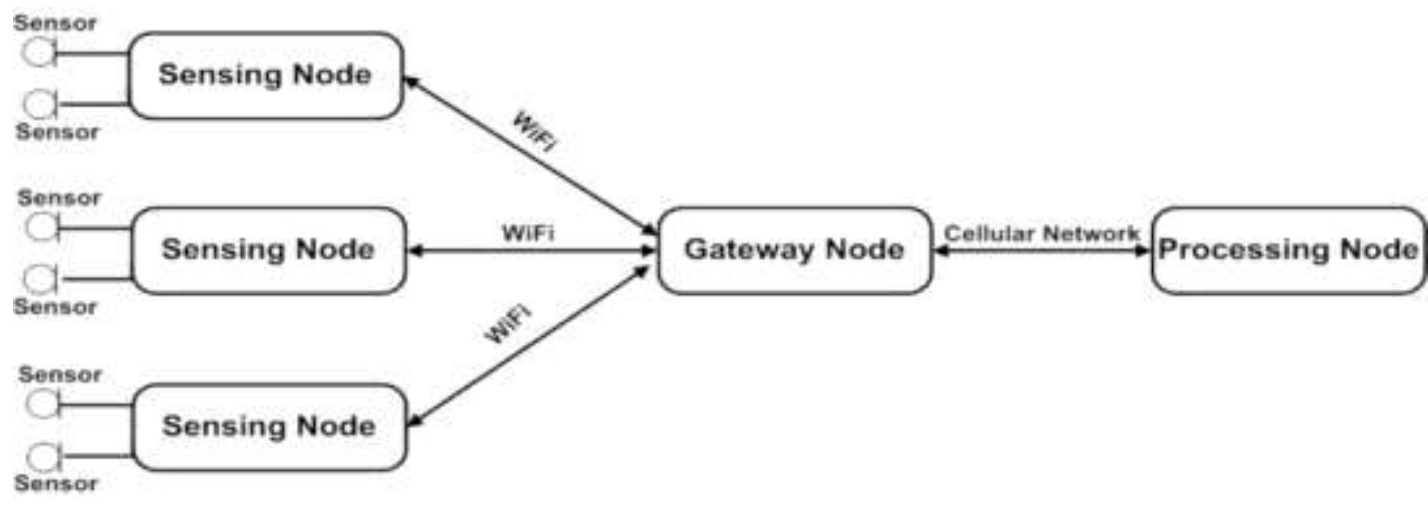

Figure 4. Architecture of the communication system

The software required for data acquisition, storage, processing and dissemination has been implemented using a layered model. Figure 5 shows the proposed layered model. This layered software architecture enables easier and better management of the applications possible. This model can be extended easily to accommodate new requirements and applications. The lowest layer (data acquisition layer) is implemented on the sensor nodes while the data transmission layer would be on the gateway nodes. All the other layers including the data cleansing and storage are implemented on the processing node (station). Handling of the storing of data within a single layer enables the data storage to be independent of applications enabling the sharing the same data by many applications possible. Data dissemination layer is implemented using the web making the access of information easier using any web browser on any device. 


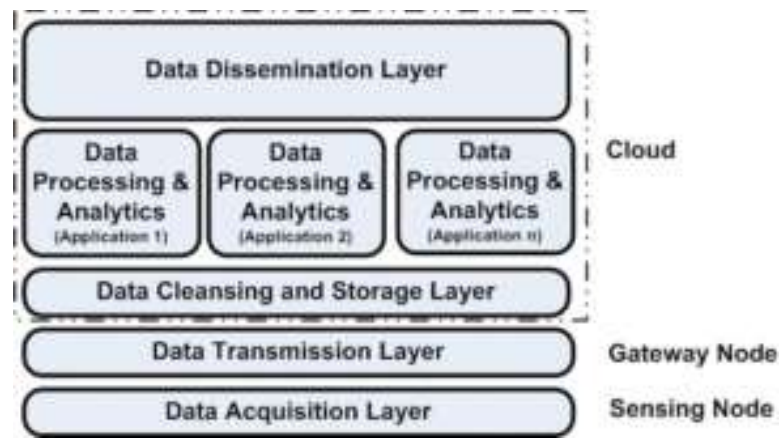

Figure 5. Software layered model

\section{EXPERIMENTS, RESULTS AND DISCUSSIONS}

For testing and calibration of the proposed weather station, the prototype was installed outside the laboratory with few sensors connected to it. Two temperature sensors for measuring the inside and outside temperatures for comparison purposes along with humidity and light intensity sensors were selected for testing. Data has been collected for several days for verifying the internal consistency of the data. But, the data collected over a 24-hour period has been selected for display purposes. Figures 6 (a), (b) and (c) show the inside temperature against the outside temperature plotted on the same graph along with humidity and light intensities respectively.

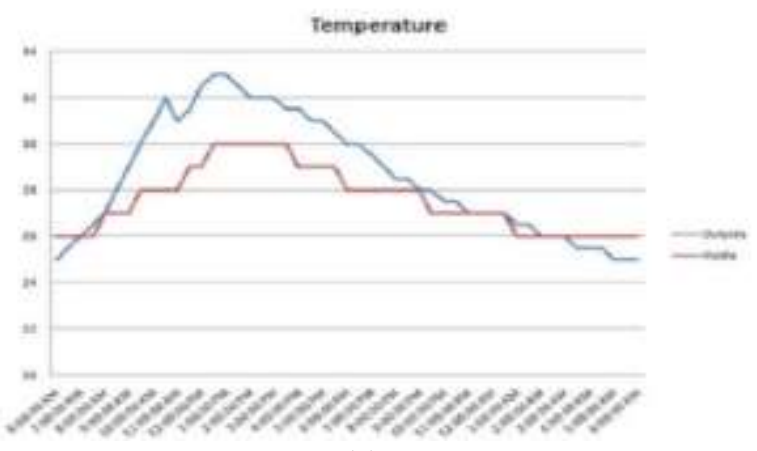

(a)

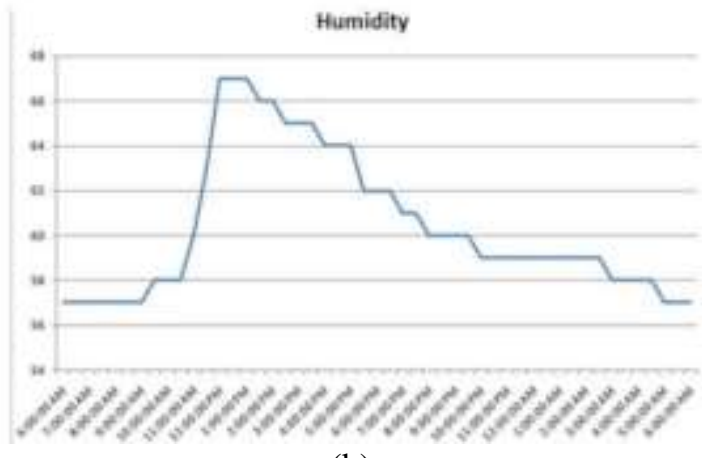

(b)

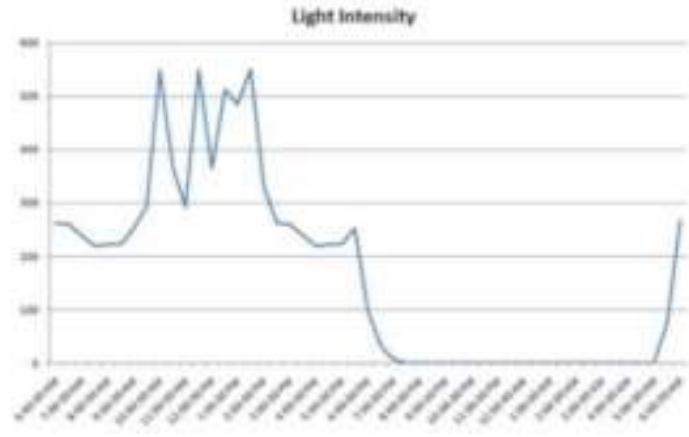

(c)

Figure 6. Experiment results

From Figure 6, it can be seen that the values obtained by the proposed system match with that of the conventional instruments such as thermometers, humidity sensors and lux meters that were used for calibration. The proposed system captures even the small momentary changes in the observed parameters. The sensitivity of the system can be modified to suit the requirement by choosing the right sensor without

\{Cloud, IoT\}-powered smart weather station for microclimate... (Mohamed Fazil Mohamed Firdhous) 
modifying other parts of the system. Similarly, the sampling interval can be easily adjusted by modifying the programmes in the sensing and gateway nodes.

\section{CONCLUSIONS}

This paper presented the design, implementation and testing of an IoT enabled smart microclimate monitoring system. The design of the system followed an open design philosophy so that it can be adapted, modified or extended to cover other applications with relative ease. The prototype was developed with few sensors, a communication module and a local display unit. The communication module will transmit the data to the cloud hosted server for further processing and dissemination. The number and types of sensors can be increased without any modification to the existing hardware and minor modification to the software. This unit can be deployed within any closed or open space depending on the requirement provided the mobile communication network is available at those locations. The power to the station has been provided by a combination of multiple sources including solar and the main grid. Power from all these sources is combined and regulated by a power controller. The power controller charges a sealed rechargeable $12 \mathrm{~V} \mathrm{Li}$-ion battery pack that would supply the system with the required power during the outage of the other on-line power sources. The system has been presently programmed to collect and upload data at every 15 minutes. This can also be modified with minor changes to the control software stored in the local storage. The test results show that the weather station works satisfactorily as the results obtained by the system matches with that of the readings obtained using conventional measuring instruments.

\section{ACKNOWLEDGEMENTS}

This work was carried out as part of the 4-times Open and Non-conventional technology for Sensing the Environment (4ONSE) project funded by the Swiss Agency for Development and Cooperation (SDC) and Swiss National Science Foundation (SNSF). The authors would like to acknowledge the funding provided by these agencies to carry out this research and the support extended by the other members of the research team.

\section{REFERENCES}

[1] T.E. Parece, J. Li, J.B. Campbell, and D. Carroll, "Assessing urban landscape variables' contributions to microclimates," Advances in Meteorology, vol. 2016, pp. 1-14, 2016.

[2] M.F.M. Firdhous, B.H. Sudantha, and P.M. Karunaratne, "IoT enabled proactive indoor air quality monitoring system for sustainable health management," in Second IEEE International Conference on Computing and Communication Technologies, Chennai, India, 2017, pp. 216-221.

[3] D.B. Markovic, R.M. Pavlovic, U.M. Pesovic, and S.S. Randic, "System for monitoring microclimate conditions in greenhouse," Acta Agriculturae Serbica, vol. XIX, no. 38, pp. 105-1141, 2014.

[4] H. Stredova, J. Knotek, and T. Streda, "Microclimate monitoring for evaluation of management effect on Mohelno Serpentine Steppe," in International Conference on Public Recreation and Landscape Protection, Brno, Czech Republic, 2015, pp. 157-160.

[5] J. Lario, and V. Soler, "Microclimate monitoring of Pozalagua cave (Vizcaya, Spain): Application to management and protection of show caves," Journal of Cave and Karst Studies, vol. 72, no. 3, pp. 169-180, 2010.

[6] H.F. Hawari, A.A. Zainal, and M.R. Ahmad, "Development of real time Internet of Things (IoT) based air quality monitoring system," Indonesian Journal of Electrical Engineering and Computer Science, vol. 13, no. 3, pp. 10391047, 2019.

[7] B.H. Sudantha, and M.F.M. Firdhous, "IEEE 1451 based smart low cost air pollution monitoring system," Discovery, vol. 47, no. 217, pp. 43-48, 2015.

[8] C.G. Boothby, "Medical prescription for a healthy building," in ASSE Professional Development Conference and Exposition, Atlanta, GA, 2016, pp. 1-8.

[9] J. Zhang, and K.R. Smith, "Indoor air pollution: A global health concern," British Medical Bulletin, vol. 68, no. 1, pp. 209-225, 2003.

[10] E. Darko, P. Heydarizadeh, B. Schoefs, and M.R. Sabzalian, "Photosynthesis under artificial light: The shift in primary and secondary metabolism," Philosophical Transactions of the Royal Society B: Biological Sciences, vol. 369, no. 1640, pp. 1-7, 2014.

[11] J. Meitalovs, A. Histjajevs, and E. Stalidzans, "Automatic microclimate controlled beehive observation system," in 8th International Scientific Confernce on Enginieering for Rural Development, Jelgava, Latvia, 2009, pp. 265-271.

[12] M. Ito, Y. Katagiri, M. Ishikawa, and H. Tokuda, "Airy notes: An experiment of microclimate monitoring in Shinjuku Gyoen garden," in Fourth International Conference on Networked Sensing Systems, Braunschweig, Germany, 2007, pp. 260-266.

[13] C.R. de Freitas, "The role and importance of cave microclimate in the sustainable use and management of show caves," Acta Carsologica, vol. 39, no. 3, pp. 477-489, 2010. 
[14] P. Merello, F.J.G. Diego, and M. Zarzo, "Microclimate monitoring of Ariadne's house (Pompeii, Italy) for preventive conservation of fresco paintings," Chemistry Central Journal, vol. 6, no. 145, pp. 1-16, 2012.

[15] R. Amjad, and M.S. Croock, "Dominated destinations of tourist inside Iraq using personal information and frequency of travel," TELKOMNIKA Telecommunication, Computing, Electronics and Control, vol. 17, no. 4, pp. 1723-1730, 2019.

[16] S. Distefano, N. Banerjee, and A. Puliafito, "Smart objects, infrastructures, and services in the Internet of Things," International Journal of Distributed Sensor Networks, vol. 2016, pp. 1-2, 2016.

[17] O. Vermesan, and P. Friess, Eds., Internet of Things: Converging technologies for smart environments and integrated ecosystems, Aalborg, Denmark: River Publishers, 2013.

[18] R. Tiwari, "An overview of Internet of Things (IoT): From literature survey to application implementation perspective," International Research Journal of Engineering and Technology, vol. 4, no. 1, pp. 575-582, 2017.

[19] A. Rghioui, and A. Oumnad, "Internet of Things: Surveys for measuring human activities from everywhere," International Journal of Electrical and Computer Engineering (IJECE), vol. 7, no. 5, pp. 2474-2482, 2017.

[20] B. Ambore, and L. Suresh, "Novel model for boosting security strength and energy efficiency in Internet-of-Things using multi-staged game," International Journal of Electrical and Computer Engineering (IJECE), vol. 9, no. 5, pp. 4326-4335, 2019.

[21] F. Mattern, and C. Floerkemeier, From Active Data Management to Event-based Systems and More, Berlin, Heidelberg: Springer-Verlag, 2010, ch. From the Internet of Computers to the Internet of Things, pp. 242-259.

[22] J. Mohammed, "Evolution of the next generation of technologies: Mobile and ubiquitous computing," International Journal of Advanced Research in Science, Engineering and Technology, vol. 1, no. 5, pp. 247-253, 2014.

[23] Y. Liu, Y. Meng, and J. Huang, "Gemini: A green deployment scheme for Internet of Things," in 22nd Wireless and Optical Communication Conference, Chongqing, China, 2013, pp. 338-343.

[24] M.A. Razzaque, M.M. Jevric, A. Palade, and S. Clarke, "Middleware for Internet of Things: A survey," IEEE Internet of Things Journal, vol. 3, no. 1, pp. 70-95, 2016.

[25] J. Shah, and B. Mishra, "Customized IoT enabled wireless sensing and monitoring platform for smart buildings," Procedia Technology, vol. 23, pp. 256-263, 2016.

[26] A.H. Ali, R.F. Chisab, and M.J. Mnati, "A smart monitoring and controlling for agricultural pumps using LoRa IOT technology," Indonesian Journal of Electrical Engineering and Computer Science, vol. 13, no. 1, pp. 286-292, 2019.

[27] F. Kamaruddin, N.N.N.A. Malik, N.A. Murad, N.M.A. Latiff, S.K.S. Yusof, and S.A. Hamzah, "IoT-based intelligent irrigation management and monitoring system using Arduino," TELKOMNIKA Telecommunication, Computing, Electronics and Control, vol. 17, no. 5, pp. 2378-2388, 2019.

[28] F. Hashim, R. Mohamad, M. Kassim, S.I. Suliman, N.M. Anas, and A.Z.A. Bakar, "Implementation of embedded real-time monitoring temperature and humidity system," Indonesian Journal of Electrical Engineering and Computer Science vol. 16, no. 1, pp. 184-190, 2019.

[29] M. Firdhous, S. Hassan, and O. Ghazali, "Monitoring, tracking and quantification of quality of service in cloud computing," International Journal of Scientific \& Engineering Research, vol. 4, no. 5, pp. 112-117, 2013.

[30] M. Firdhous, S. Hassan, and O. Ghazali, "A comprehensive survey on quality of service implementations in cloud computing," International Journal of Scientific \& Engineering Research, vol. 4, no. 5, pp. 118-123, 2013.X. S.

\section{BIOGRAPHIES OF AUTHORS}

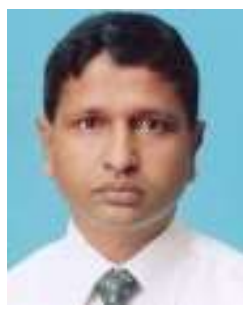

Dr. Mohamed Fazil Mohamed Firdhous is a Senior Lecturer and the Director of Postgraduate Studies at the Faculty of Information Technology, University of Moratwua, Sri Lanka. He is engaged in undergraduate and postgraduate teaching along with cutting edge research in the areas of trust and trust management in cloud computing, Internet of Things, mobile adhoc networks, vehicular networks, computer security, environment monitoring, intelligent transport systems and rural ICT development. He has teaching, research and industry experience in many countries including Sri Lanka, Singapore, United States of America and Malaysia. In addition to his teaching and research activities, he is a highly sought after ICT consultant to the government and private institutions in Sri Lanka.

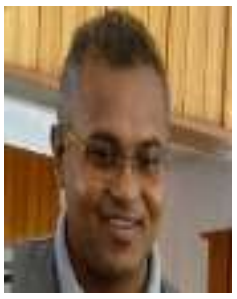

Mr. B.H Sudantha is the Head of the Department of Information Technology and the Director, Information Technology Research Unit (ITRU) at the Faculty of Information Technology, University of Moratwua, Sri Lanka. Sudantha obtained his undergraduate and postgraduate degrees in Physics specializing in semiconductor devices at the University of Sri Jayewardenepura, Sri Lanka. He is currently engaged in undergraduate and postgraduate teaching in the broad areas of computer architecture with special emphasis on embedded processing. Sudantha's main research areas include environment monitoring, intelligent transposrt systems, mobile robotics and micro controller enabled device design. 